\title{
Article \\ Alleviation Effects of Bifidobacterium animalis subsp. lactis XLTG11 on Dextran Sulfate Sodium-Induced Colitis in Mice
}

\author{
Nana Wang ${ }^{1,2,+}$, Song Wang ${ }^{1,2,+} \mathbb{D}$, Baofeng $\mathrm{Xu}{ }^{1,2}$, Fei Liu ${ }^{1,2}$, Guicheng Huo ${ }^{1,2}$ and Bailiang Li ${ }^{1,2, *}$ \\ 1 Key Laboratory of Dairy Science, Ministry of Education, Northeast Agricultural University, \\ Harbin 150030, China; nanawang1017@163.com (N.W.); ws_1984@163.com (S.W.); \\ xubaofeng93@163.com (B.X.); david.as@163.com (F.L.); guichenghuo@126.com (G.H.) \\ 2 Food College, Northeast Agricultural University, Harbin 150030, China \\ * Correspondence: 15846092362@163.com; Tel.: +86-451-5519-0426 \\ + These authors have contributed equally to this work.
}

Citation: Wang, N.; Wang, S.; Xu, B.; Liu, F.; Huo, G.; Li, B. Alleviation Effects of Bifidobacterium animalis subsp. lactis XLTG11 on Dextran Sulfate Sodium-Induced Colitis in Mice. Microorganisms 2021, 9, 2093. https://doi.org/10.3390/ microorganisms 9102093

Academic Editors: Christine Bäuerl and Gaspar Pérez-Martínez

Received: 30 July 2021

Accepted: 30 September 2021

Published: 3 October 2021

Publisher's Note: MDPI stays neutral with regard to jurisdictional claims in published maps and institutional affiliations.

Copyright: () 2021 by the authors. Licensee MDPI, Basel, Switzerland. This article is an open access article distributed under the terms and conditions of the Creative Commons Attribution (CC BY) license (https:// creativecommons.org/licenses/by/ $4.0 /)$.
Abstract: Inflammatory bowel disease (IBD) is a chronic immune-related disease, which can occur through the dysfunction of the immune system caused by the imbalance of gut microbiota. Previous studies have reported the beneficial effects of Bifidobacterium on colitis, while the related mechanisms behind these effects have not been fully elucidated. The aim of our study is to investigate the alleviation effect of Bifidobacterium animalis subsp. lactis XLTG11 (B. lactis) on dextran sulfate sodium (DSS)-induced colitis and its potential mechanism. The results showed that B. lactis XLTG11 significantly decreased weight loss, disease activity index score, colon shortening, myeloperoxide activity, spleen weight, and colon tissue damage. Additionally, B. lactis XLTG11 significantly decreased the levels of pro-inflammatory cytokines and increased the level of anti-inflammatory cytokine. Meanwhile, high doses of $B$. lactis XLTG11 significantly up-regulated the expression of tight junction proteins and inhibited activation of Toll-like receptor 4 (TLR4)/myeloid differentiation factor 88 (MYD88)/nuclear factor-kB (NF-kB) signaling pathway. Furthermore, B. lactis XLTG11 increased the gut microbiota diversity and modulated gut microbiota composition caused by DSS. Moreover, Spearman's correlation analysis also found that several specific gut microbiota were significantly correlated with colitis-related indicators. These results demonstrated that B. lactis XLTG11 can alleviate DSS-induced colitis by inhibiting the activation of the TLR4/MYD88/NF- $\mathrm{kB}$ signaling pathway, regulating inflammatory cytokines, improving intestinal barrier function, and modulating the gut microbiota.

Keywords: Bifidobacterium animalis subsp. lactis; colitis; inflammation; tight junction proteins; gut microbiota

\section{Introduction}

Inflammatory bowel disease (IBD) is a chronic and recurrent autoimmune disease that includes ulcerative colitis (UC) and Crohn's disease (CD). Although IBD is a global health burden with the highest incidence in Western countries, the incidence in newly industrialized countries such as Asia, Africa, and South America has shown a rapid upward trend [1]. The specific pathogenesis of IBD remains unclear, accumulating data indicates that genetic susceptibility, abnormal immune response, damaged intestinal barrier, and intestinal microflora imbalances play a vital role in the occurrence and progression of IBD [2-4]. The traditional drugs, including aminosalicylates, immunosuppressants, and biological drugs in patients with IBD, pose serious side effects, such as headache, nausea, and infection $[2,5,6]$. Therefore, it is important to develop effective and harmless alternative strategies to alleviate IBD symptoms. 
The gut microbiota plays a crucial role in human energy metabolism and immunity. There is growing evidence that an unfavorable alteration of gut microbiota is associated with the development of human diseases, such as obesity, allergy, IBD, and type 2 diabetes $[3,7,8]$. The composition of gut microbiota is closely related to the host immune system [9]. Firmicutes and Bacteroidetes are the most abundant in gut microbiota, which is closely related to intestinal health [10]. Compared with healthy individuals, the decrease of Bacteroides and increase of Firmicutes are observed in patients with IBD [11-13]. It has been demonstrated that potential pathogenic bacteria (Escherichia coli and Proteobacteria) are increased in patients with UC when compared to healthy subjects [14]. The pathogenic bacteria invade intestinal epithelial cells, stimulate inflammation, damage the integrity of the intestinal epithelial barrier, and triggers intestinal inflammatory responses [15]. Thus, gut microbiota might be a potential and important target for UC therapy.

Probiotics are live microorganisms that colonize the human intestine to exert beneficial effects on the intestinal tract [16]. Particularly, Lactobacilli and Bifidobacteria are the two main probiotic candidates for intervention in intestinal inflammation [17]. Bifidobacteria probiotics play specific roles in reducing the relative abundance and colonization of conditioned pathogens, host-microbial homeostasis, protecting the integrity of the intestinal mucosal barrier, and intestinal inflammation regulation [18-21]. Moreover, several researchers have reported the beneficial effects of Bifidobacterium on colitis. Previous studies found that Bifidobacterium breve was effective in alleviating DSS-induced colitis by inhibiting the inflammatory cytokines, enhancing the intestinal epithelial barrier, and regulating the gut microbiota. Din et al. indicated that Bifidobacterium bifidum ATCC 29521 alleviated DSS-caused ulcerative colitis by modulating miRNA-associated tight junction proteins and NF- $\mathrm{KB}$ regulation and by partially restoring dysbiosis [22]. However, the related mechanisms of Bifidobacterium improve colitis have not been fully elucidated.

Bifidobacterium animalis subsp. lactis XLTG11 was found to have strong acid and bile salts tolerance, high cell adhesion properties, and anti-inflammatory ability in vitro. Therefore, this study aimed to investigate the alleviation effect of B. lactis XLTG11 on DSSinduced colitis in mice and its potential mechanism. In the current study, Disease activity index (DAI) score, colon length, MPO activity, spleen index, and histopathological analysis were determined to evaluate the effect of B. lactis XLTG11 on DSS-induced colitis. We investigated the inflammatory cytokines, intestinal barrier key gene expression, TLR4/NF$\kappa \mathrm{B}$ signaling pathway, and gut microbiota to assess the potential mechanisms involved. Our results would provide a new insight for probiotics of B. lactis XLTG11 to alleviate colitis.

\section{Materials and Methods}

\subsection{Bacterial Strain and Culture}

Bifidobacterium animalis subsp. lactis XLTG11 was isolated from Healthy children's intestines in China and preserved at China General Microbiological Culture Collection Center. The strain was anaerobically cultured in modified De Man Rogosa Sharpe (mMRS) medium (Hopebio Company, Qingdao, China, HB0384-5) supplemented with 0.05\% Lcysteine hydrochloride under conditions at $37^{\circ} \mathrm{C}$ for $18 \mathrm{~h}$ and sub-cultured twice prior to the experiment. The Bacteria were obtained by centrifugation $\left(6000 \times g\right.$ for $10 \mathrm{~min}$ at $\left.4{ }^{\circ} \mathrm{C}\right)$ and washed three times with sterile phosphate-buffered saline (PBS). The B. lactis XLTG11 was re-suspended at $1 \times 10^{7}$ and $1 \times 10^{8} \mathrm{CFU} / \mathrm{mL}$ in PBS buffer.

\subsection{Animals and Experimental Design}

Eight-week-old specific pathogen-free (SPF) C57BL/6 male mice were purchased from Beijing Vital River Laboratory Animal Technology Co., Ltd. (Beijing, China). The mice were housed at an ambient condition under $23 \pm 2{ }^{\circ} \mathrm{C}, 50 \pm 10 \%$ humidity, and $12 \mathrm{~h}$ of the light-dark cycle. All animal procedures were performed in accordance with the Guidelines for Care and Use of Laboratory Animals of Northeast Agricultural University and the experiments were approved by the Animal Ethics Committee of Northeast Agricultural University (ethic approval code: NEAUEC2001119). All animals were acclimatized for one 
week prior to the experiments. The mice were randomly divided into four groups: normal control group (NC), model control group (MC), low doses of B. lactis XLTG11 (BL), and high doses of $B$. lactis XLTG11 (BH). During the whole experiment, the BL and BH groups were treated with low doses of $B$. lactis XLTG11 $\left(1 \times 10^{7} \mathrm{CFU} / \mathrm{d}\right)$, high doses of B. lactis XLTG11 $\left(1 \times 10^{8} \mathrm{CFU} / \mathrm{d}\right)$ by oral gavage once daily, respectively. The NC and MC groups were gavaged with $200 \mu \mathrm{L}$ PBS once daily at the same feeding frequency. From days 15 to 21, all mice except the NC group received 2.5\% DSS (Alphabio, Tianjin, China) dissolved in drinking water to induce colitis [23]. During DSS treatment, the bodyweight of all mice was measured every day, and the DAI score was recorded according to bodyweight loss, stool consistency, and gross blood as previously described [2].

At the end of the experiments, the mice were fasted for $12 \mathrm{~h}$, anesthetized with ether, due to the strong anesthetic effect, good safety, and muscle relaxation effect [24,25]. The blood samples of all mice were collected by taking the eyeballs and serum was obtained by centrifuged for $15 \mathrm{~min}$ at $1500 \times g$ at $4{ }^{\circ} \mathrm{C}$ and stored at $-80^{\circ} \mathrm{C}$. The colon contents were collected under sterile conditions and then stored at $-80^{\circ} \mathrm{C}$ for gut microbiota analysis. The colon length was measured and washed with ice-cold physiological saline, then resected colon tissue was fixed in $4 \%$ paraformaldehyde immediately for histopathological analysis, and the remaining tissues were stored at $-80{ }^{\circ} \mathrm{C}$ for a real-time quantitative polymerase chain reaction. The spleen was also harvested and weighed, and the spleens index was calculated as follows: spleens index $(\%)=\frac{\text { liver weight }}{\text { body weight }} \times 100$.

\subsection{Histopathological Analysis}

The distal colon was fixed in $4 \%$ paraformaldehyde for $48 \mathrm{~h}$, embedded in paraffin, and cut into $5 \mu \mathrm{m}$ sections. These slices were dewaxed with xylene and then stained with hematoxylin and eosin (H\&E) for observation. Histological scores were calculated as described previously [26].

\subsection{Colonic MPO Activity and Serum Proinflammatory Cytokines}

The colonic tissues of mice in different treatment groups were weighed and homogenized in the manufacturer's stocking buffer (1:19), then measured by the myeloperoxide (MPO) test kit (Nanjing Jiancheng Bioengineering Institute, Nanjing, China) according to the manufacturer's instructions. The levels of interleukin-1 $\beta$ (IL-1 $\beta$ ), IL-10, IL-6, and tumor necrosis factor-alpha (TNF- $\alpha$ ) in serum were measured with the ELISA kits (Quanzhou Kenuodi Bio-Technology Co., Ltd., Quanzhou, China) according to the manufacturer's instructions.

\subsection{Real-Time Quantitative Polymerase Chain Reaction ( $q R T-P C R$ )}

The relative mRNA levels of tight junction protein genes (claudin-1, occluding and ZO-1) and TLR4 signaling pathway related genes (TLR4, MYD88 and NF- $\mathrm{B}$ ) were detected by quantitative real-time polymerase chain reaction (qRT-PCR), and GAPDH gene was used as an internal reference gene. The primers used for qRT-PCR were described in previous studies [27]. Total RNA of the colon was extracted with RNAiso Plus ((Takara Biotechnology, Dalian, China) and quantified by using 2000C Ultra-micro UV spectrophotometer (Thermo Fisher Scientific Inc., Waltham, MA, USA). The mRNA was reverse transcribed into cDNA with Transcriptor First Strand cDNA Synthesis Kit (Roche, Germany, 04897030001). qRT-PCR was carried out according to the instructions on the Bio-Rad CFX96 real-time PCR System (Bio-Rad, Foster City, CA, USA) using Stormstar Sybrgreen qPCR Master Mix kit (DBI Bioscience, Ludwigshafen, Germany, DBI-2143). The expression of related genes was analyzed using the $2^{-\Delta \Delta \mathrm{CT}}$ method. 


\subsection{Gut Microbiota Analysis}

The colon microbiota genomic DNA in each group $(n=3)$ was extracted using the E.Z.N.A. ${ }^{\circledR}$ Stool DNA Kit (Omega Bio-Tek, Norcross, GA, USA) according to the manufacturer's recommendations. The V3-V4 region of the bacterial $16 \mathrm{~S}$ rDNA was amplified by PCR using the 338F and 806R primers: (5'-ACTCCTACGGGAGGCAGCAG-3') (forward primer) and (5'- GGACTACHVGGGTWTCTAAT-3') (reverse primer). The resulting PCR was purified using an AxyPrep DNA gel extraction kit (Axygen Biosciences, Union City, CA, USA), and quantified using Qubit 2.0 Fluorometer (Life Technologies, Carlsbad, CA, USA). Sequencing was performed on the Illumina Miseq platform (Illumina Inc., San Diego, CA, USA) according to standard protocols. The raw data was merged with Flash (V1.2.11) software and filtered by QIIME (V1.9.1) to collect the high-quality clean tags [28,29]. The effective tags were clustered by UCLUST (version 1.2.22) into OTUs of $\geq 97 \%$ similarity [30]. OTUs were analyzed based on the Greengenes database by PyNAST software (Version 1.2) and annotated with taxonomic information at phylum and genus levels [31].

\subsection{Statistical Analysis}

All data were analyzed using SPSS 22.0 software (SPSS Inc., Chicago, IL, USA) and expressed as the mean \pm standard deviation (SD). The statistical difference was determined using one-way ANOVA, followed by Duncan's multiple range test. The relationship between dominant gut microbiota and UC-related symptoms was applied by spearman correlation. $p$-value $<0.05$ were considered to be statistically significant.

\section{Results}

\subsection{Effects of B. lactis XLTG11 on DSS-Induced Colitis Symptoms}

The body weight during DSS induction was measured in Figure 1A. The NC group showed a steady increase in body weight, but the bodyweight of mice in the MC group showed a significant decrease trend from day 17 until the end of the experiment $(p<0.05)$. Both BL and BH treatment groups reversed these changes to some extent, and the bodyweight of the BH group was significantly higher than that of the MC group $(p<0.05)$. The changes in DAI scores were shown in Figure 1B. The DAI scores of the NC group remained at 0 , while the DAI score for the $\mathrm{MC}$ group showed a rapid increase trend compared to those of the NC group $(p<0.05)$. The increments in DAI scores for the BL and BH groups were significantly smaller than that of the MC group $(p<0.05)$. The colon length of the mice in four groups was shown in Figure 1C. Compared with the NC group, the colon length showed a significant reduction in the MC group $(p<0.05)$. After the intervention, the symptoms of colon shortening caused by DSS appeared mitigated $(p<0.05)$. As shown in Figure 1D, compared with the NC group, the MPO activity of mice in the MC group was significantly increased $(p<0.05)$, but compared with the MC group, the MPO activity was significantly decreased in a dose-dependent manner in the BL group and $\mathrm{BH}$ group $(p<0.05)$, and there was no significant difference between NC group and $\mathrm{BH}$ group $(p<0.05)$. The spleen indexes in each treatment group were shown in Figure 1E. We observe that the mice in the MC group were substantially higher compared with the NC group $(p<0.05)$, but both doses of $B$. lactis XLTG11 administrations reversed these changes, and the trend in the $\mathrm{BH}$ group was more similar to the NC group. These results indicated that $B$. lactis XLTG11 effectively relieved DSS-induced colitis symptoms. 

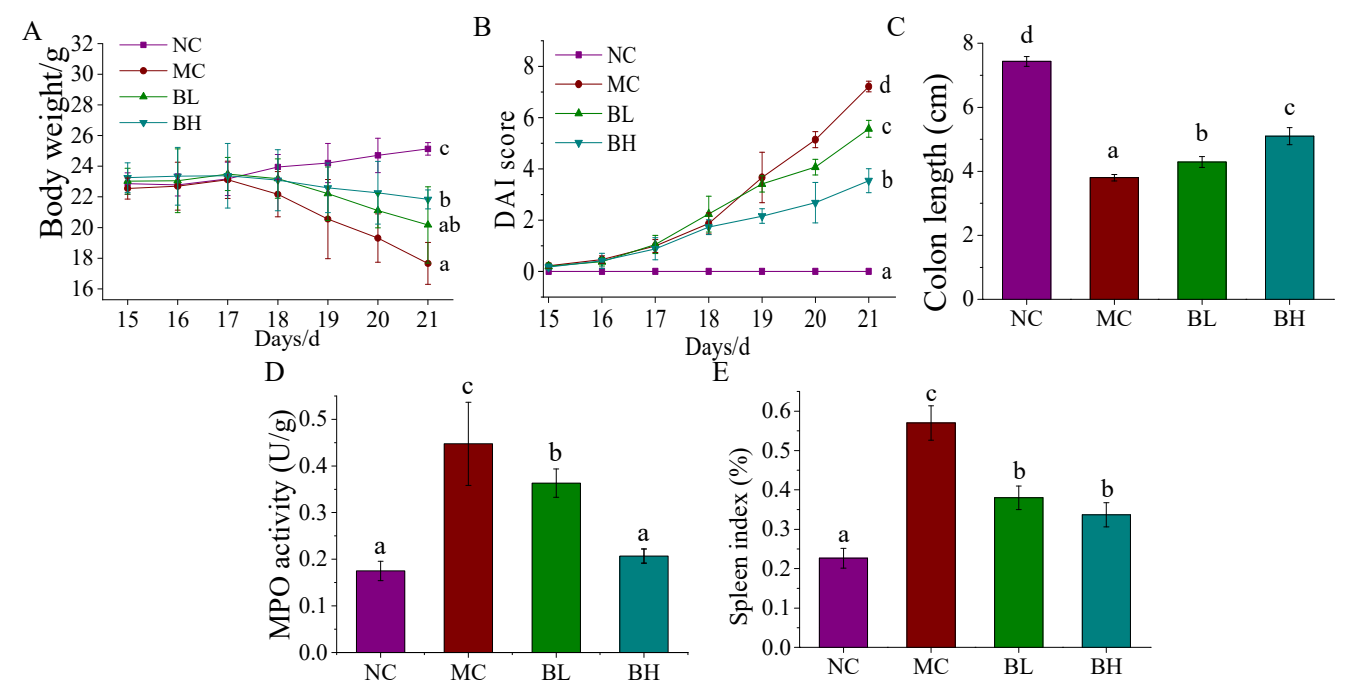

Figure 1. Effects of B. lactis XLTG119 on DSS-induced colitis symptoms. (A) Bodyweight; (B) DAI score; (C) Colon length; (D) MPO activity; (E) spleen index. NC, normal control group; MC, model control group; BL, low-dose B. lactis XLTG11; BH, high-dose B. lactis XLTG11. All data are expressed as mean \pm SD. Different letters indicate statistically significant differences $(p<0.05)$ between the groups.

\subsection{Effects of B. lactis XLTG11 on Colon Histopathological Analysis}

The Histological changes in each treatment group were shown in Figure 2A. The colon tissue of the NC group showed complete goblet cells and intact epithelial tissue, but the crypt structure and goblet cells of the colon tissue of the mice in the MC group were disappeared, and the inflammatory cells infiltrated. After being treated with $B$. lactis XLTG11, the colonic tissues in the BL group and BH group showed improved structural damage and reduced inflammatory cell infiltration. In addition, compared with the MC group, both doses of $B$. lactis XLTG11 administrations dramatically reduced histology scores caused by DSS (Figure $2 \mathrm{~B} ; p<0.05$ ). In particular, the BH group showed a higher ability to reduce the pathological score relative to the BL group, which was closer to the NC group. These findings demonstrated that a high-dose B. lactis XLTG11 significantly improved tissue morphological changes induced by DSS and reduced histology scores.

A

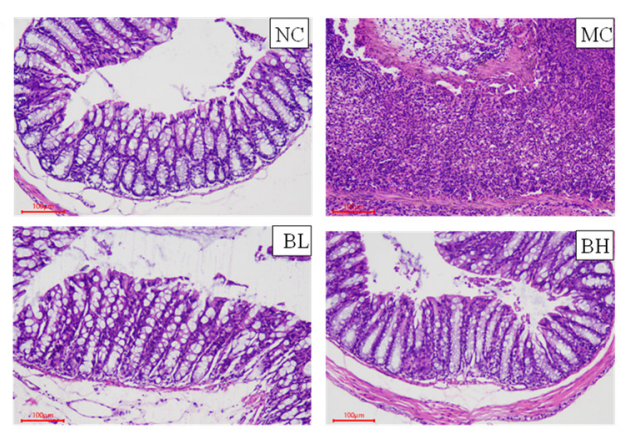

B

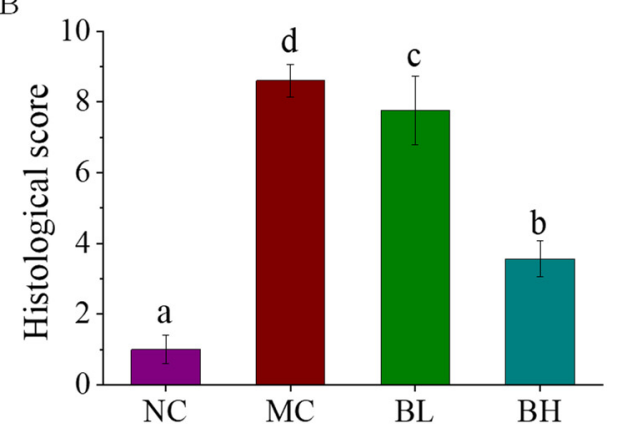

Figure 2. Effects of B. lactis XLTG11 on colon histopathological analysis. (A) Histological images; (B) Histological score. NC, normal control group; MC, model control group; BL, low-dose B. lactis XLTG11; BH, high-dose B. lactis XLTG11. All data are expressed as mean $\pm \mathrm{SD}$. Different letters indicate statistically significant differences $(p<0.05)$ between the groups. 


\subsection{Effects of B. lactis XLTG11 on Inflammatory Cytokines}

The levels of inflammatory cytokines in the serum of mice in all groups were shown in Figure 3. The levels of pro-inflammatory cytokines (including IL-1 $\beta$, TNF- $\alpha$, and IL-6) significantly increased in the mice in the MC group than that in the NC group. While the levels of IL- $1 \beta$ and IL- 6 in both doses of B. lactis XLTG11 administrations were lower than that of the MC group $(p<0.05)$. Especially, compared with the NC group, there was no significant difference in the level of IL-6 between the high-dose B. lactis XLTG11 group and the NC group $(p>0.05)$. The serum IL-10 levels in the MC group were significantly lower than that of the NC group $(p<0.05)$. Conversely, the levels of IL-10 were significantly reversed by high-dose B. lactis XLTG11 interventions $(p<0.05)$, but these changes were not significant in the BL and MC group $(p>0.05)$. The abovementioned data showed that high-dose B. lactis XLTG11 administration could effectively inhibit inflammation symptoms caused by DSS relative to the BL group.

A

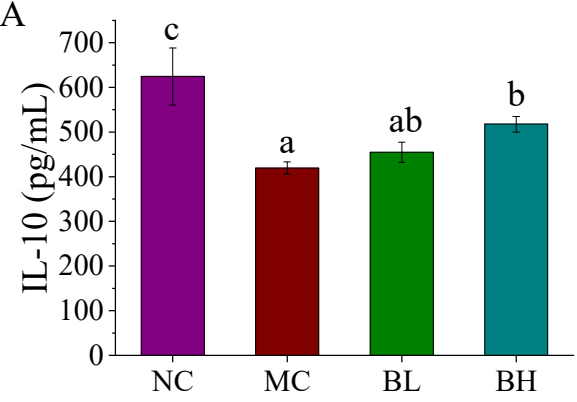

$\mathrm{C}$

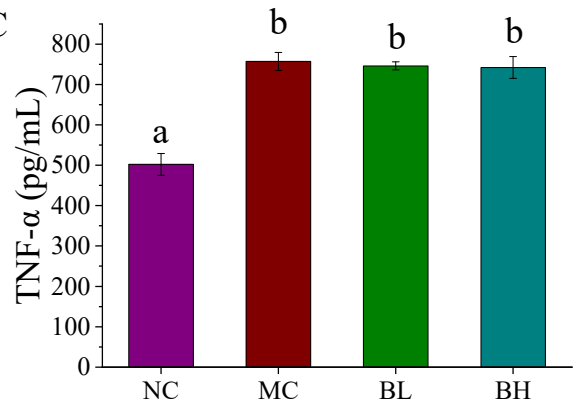

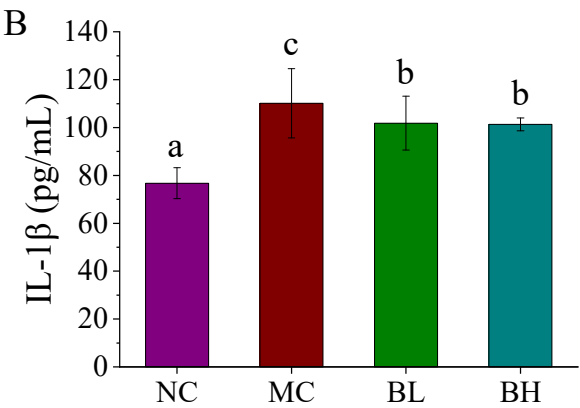

D

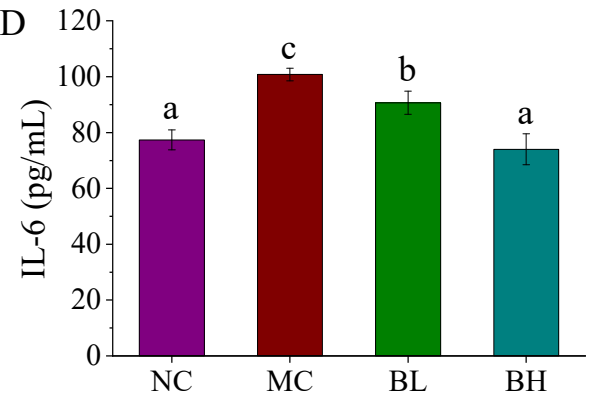

Figure 3. Effects of $B$. lactis XLTG11 on inflammatory cytokines. (A) IL-10; (B) IL-1 $\beta$; (C) TNF- $\alpha$ and (D) IL-6. NC, normal control group; MC, model control group; BL, low-dose B. lactis XLTG11; BH, high-dose $B$. lactis XLTG11. All data are expressed as mean \pm SD. Different letters indicate statistically significant differences $(p<0.05)$ between the groups.

\subsection{Effects of B. lactis XLTG11 on Claudin-1, Occludin, and ZO-1 mRNA Expression}

The tight junction proteins (claudin-1, occludin, and ZO-1) in the colon were shown in Figure 4. Compared with the NC group, the expression levels of claudin-1 and ZO-1 in the MC group were significantly decreased $(p<0.05)$, implying that the epithelial integrity has been impaired. Compared with the MC group, the expression levels of claudin-1 and ZO-1 were significantly reversed by high-dose B. lactis XLTG11 supplementation $(p<0.05)$, but these changes were not significant in the low-dose B. lactis XLTG11 and MC group $(p>0.05)$. In addition, the occludin mRNA expression levels in the MC group were no significant differences when compared to the NC group $(p>0.05)$. Noticeably, after high-dose B. lactis XLTG11 supplementation, the expression levels of occludin were pronouncedly increased than that in the MC group. These results showed that the high dose of B. lactis XLTG11 supplementations could ameliorate the intestinal barrier function induced by DSS. 
A

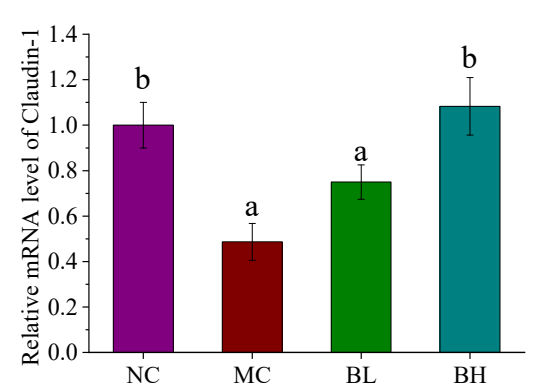

B

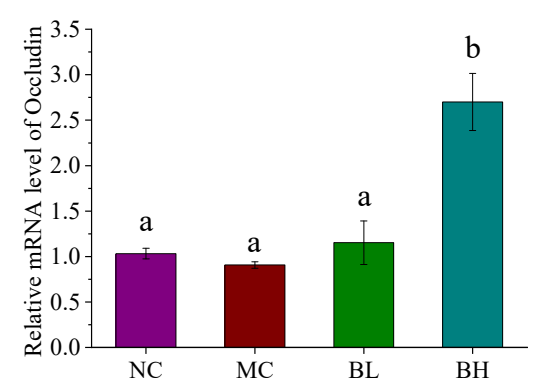

$\mathrm{C}$

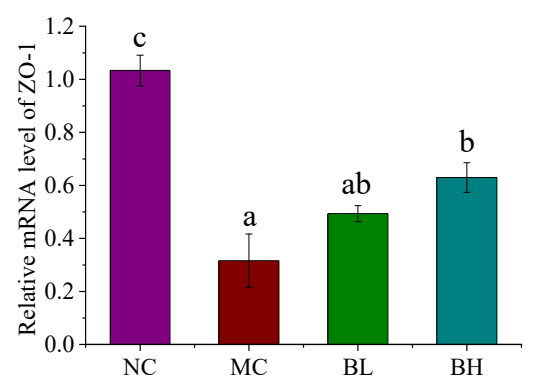

Figure 4. Effects of B. lactis XLTG11 on claudin-1 (A), occluding (B), and ZO-1 (C) mRNA expression in colon tissues were detected by qRT-PCR. NC, normal control group; MC, model control group; BL, low-dose B. lactis XLTG11; BH, high-dose B. lactis XLTG11. All data are expressed as mean \pm SD. Different letters indicate statistically significant differences $(p<0.05)$ between the groups.

\subsection{Effects of B. lactis XLTG11 on the TLR4/MYD88/NF-kB Signaling Pathway}

To investigate whether the TLR4/MYD88/NF-kB signaling pathway plays a significant role in the regulation of B. lactis XLTG11 on anti-inflammatory mechanisms, the mRNA expression levels of its related genes were measured. As shown in Figure 5, DSS administration remarkably increased the mRNA expression levels of TLR4, MYD88 and NF-kB compared to those of the NC group $(p<0.05)$. Conversely, the TLR4 and NF-kB gene expression were observably down-regulated in the $\mathrm{BH}$ groups $(p<0.05)$, but there were no significant differences between the BL and MC groups $(p>0.05)$. Furthermore, both doses of $B$. lactis XLTG11 dramatically down-regulated the mRNA expression of MYD88 when compared with the MC group $(p<0.05)$. Especially, treatment with the high-dose $B$. lactis XLTG11 was similar to that of the NC group $(p>0.05)$. These findings indicated that a high-dose $B$. lactis XLTG11 exerted its anti-inflammatory function by inhibiting TLR4/MYD88/NF-kB activation.
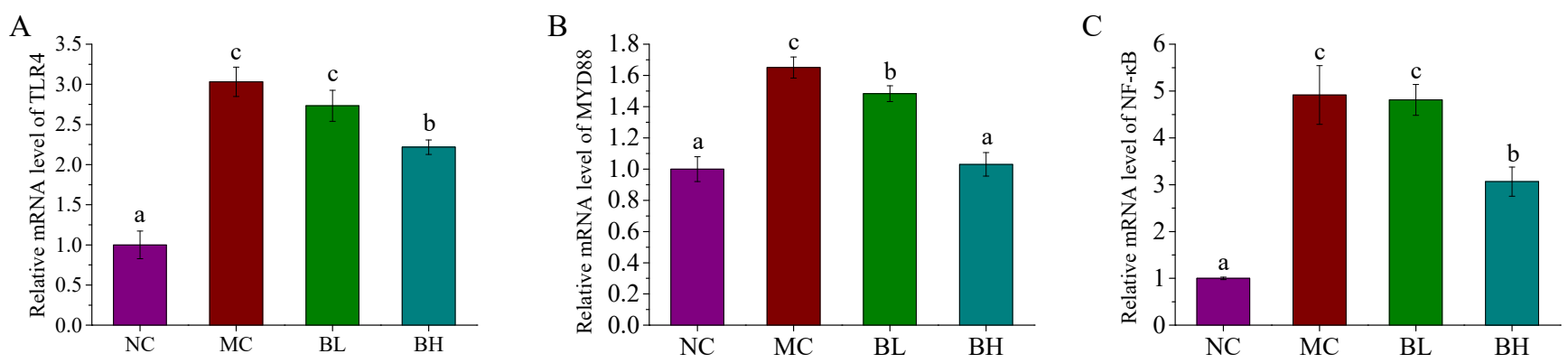

Figure 5. Effects of B. lactis XLTG11 on TLR4 (A), MYD88 (B), and NF-kB (C) mRNA expression levels in colon tissues were detected by qRT-PCR. NC, normal control group; MC, model control group; BL, low-dose B. lactis XLTG11; BH, high-dose B. lactis XLTG11. All data are expressed as mean \pm SD. Different letters indicate statistically significant differences $(p<0.05)$ between the groups.

\subsection{Effects of B. lactis XLTG11 on Structure and Composition of Gut Microbiota}

Three out of the 8 mice were randomly selected as part of an exploratory pilot analysis. The gut microbiota of the colonic contents among different groups were analyzed by sequencing the V3-V4 hypervariable region of the 16S rDNA gene. The observed_species of the mice in the MC group was not significantly different from that in the NC group (Figure 6A), and Simpson index of the mice in the MC group was higher than that in the NC group (Figure 6B), implying that DSS intake resulted in changes in the microbial diversity. Whereas, B. lactis XLTG11 administration reversed these changes to a certain extent. 
A

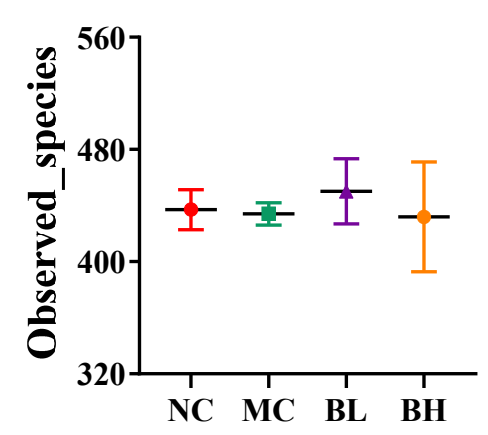

B

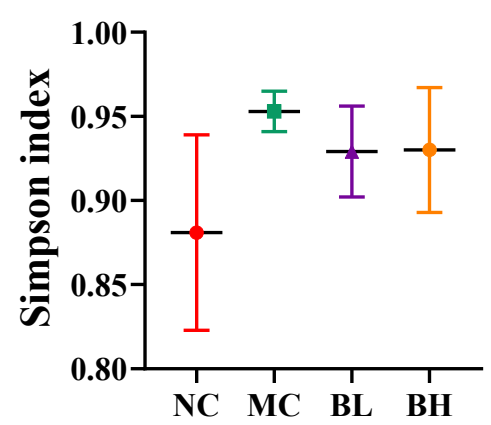

$\mathrm{C}$

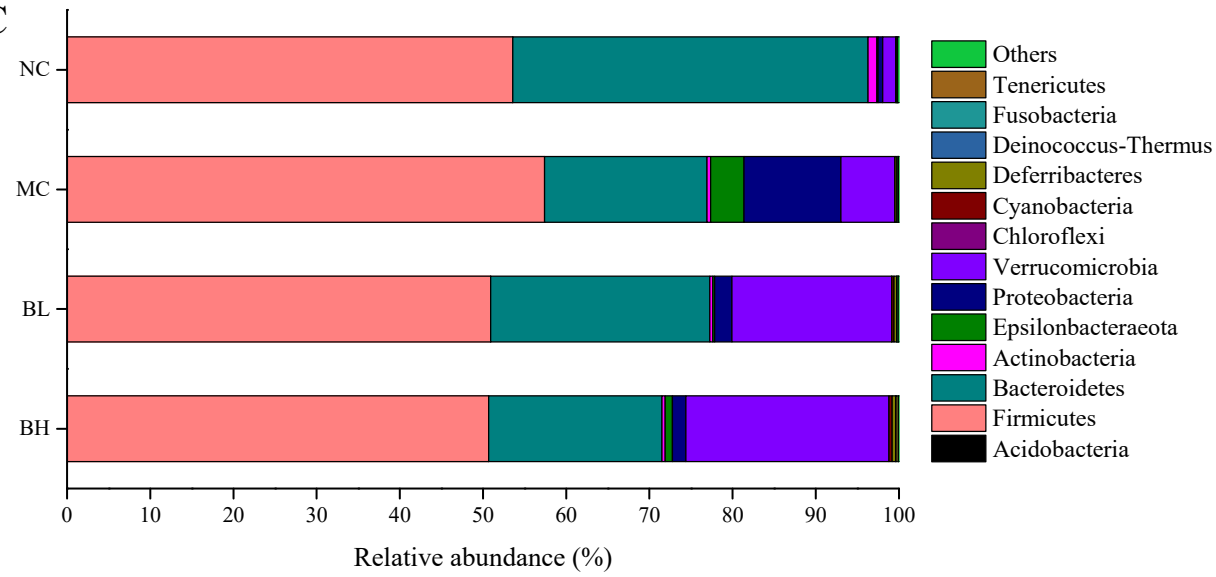

$\mathrm{D}$

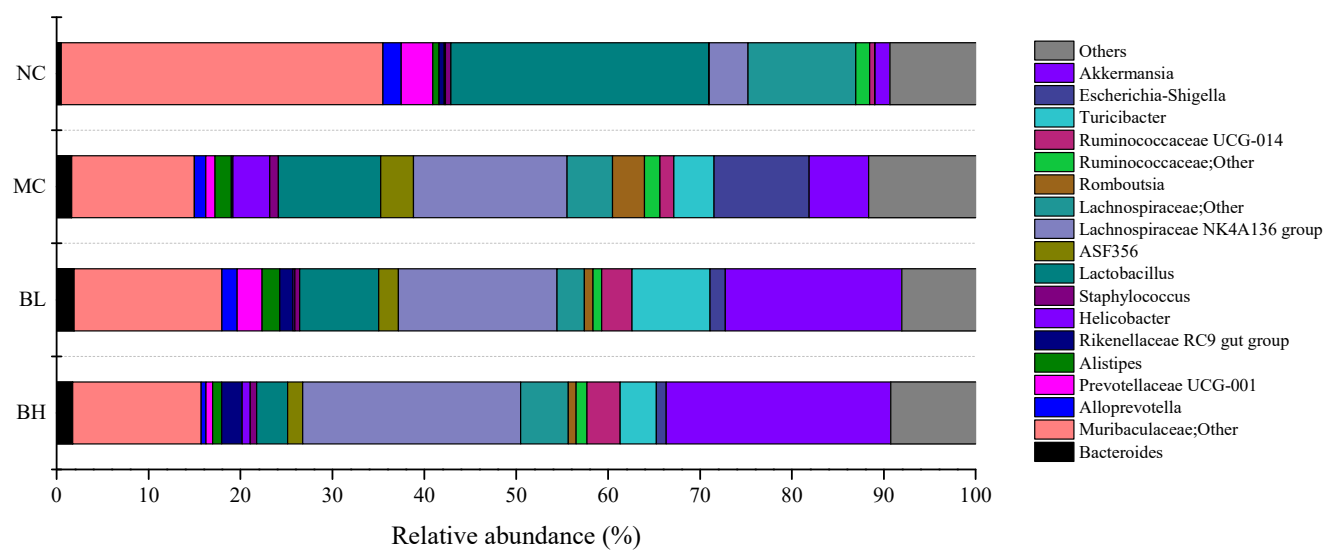

Figure 6. Effects of B. lactis XLTG11 on structure and composition of gut microbiota. (A) Observed_species; (B) Simpson index; (C) Gut microbiota composition at the phylum level; (D) Gut microbiota composition at the genus level. NC, normal control group; $\mathrm{MC}$, model control group; $\mathrm{BL}$, low-dose B. lactis XLTG11; BH, high-dose B. lactis XLTG11.

At the phylum level, compared with the NC group, reduced relative abundances of Bacteroidetes and increased relative abundances of Firmicutes, Epsilonbacteraeota and Proteobacteria were observed in the MC group (Figures 6C and S1). Therefore, the Firmicutes/Bacteroidetes (F/B) ratio was higher than the other groups. However, the F/B ratio, Epsilonbacteraeota and Proteobacteria were reduced in the $\mathrm{BL}$ and $\mathrm{BH}$ group to similar levels as those in the NC group. At the genus levels (Figures 6D and S2), the relative abundances of Helicobacter, Escherichia-Shigella, Romboutsia, and Staphylococcus was higher in the MC group than that in the NC group $(p<0.05)$. The relative abundance of Helicobacter was significantly decreased in BL group $(p<0.05)$. Furthermore, the relative abundance of Muribaculaceae; Other was significantly decreased and Lachnospiraceae NK4A136 group was significantly increased in the MC group compared to the NC group $(p<0.05)$. B. 
lactis XLTG11 supplementation increased the relative abundance of Muribaculaceae;Other, Ruminococcaceae UCG-014, Lachnospiraceae NK4A136 group and Akkermansia to some extent, although the changes are not statistically different. Compared with the NC group, the relative abundances of Alistipes and Turicibacter in the MC group were increased $(p>0.05)$. Whereas the relative abundances of Alistipes was decreased only in the high-dose group compared to the MC group $(p>0.05)$. Interestingly, both low-dose and high-dose B. lactis XLTG11 administration reduced the proportion of Lactobacillus compared to the MC group $(p>0.05)$.

\subsection{Correlation Analysis between UC-Related Symptoms, Related Gene Expression and Dominant Gut Microbiota}

To determine the role of gut microbiota in alleviating inflammation biomarkers, the correlation between UC-related symptoms, related gene expression, and dominant gut microbiota at the genus levels was analyzed (Figure 7). The relative abundance of Bacteroides was significantly positively correlated with IL- $1 \beta$, TNF- $\alpha$, TLR4, and NF- $k B$, while was significantly negatively correlated with IL-10 and ZO-1. Unclassified Muribaculaceae genus and Alloprevotella were positively associated with IL-10 and ZO-1, while was negatively associated with IL-1 $\beta$, TNF- $\alpha$, TLR4, MYD88, and NF-kB. However, the Alistipes was positively associated with TLR4 and NF- $\mathrm{KB}$ but was significantly negatively correlated with IL-10 and ZO-1. The relative abundance of Helicobacter was positively associated with IL-1 $\beta$. The relative abundances of Lactobacillus were significantly negatively correlated with TNF- $\alpha$, while was significantly positively correlated with ZO- 1 . The relative abundances of ASF356 were positively correlated with the pro-inflammation cytokines (IL-1 $\beta$, TNF- $\alpha$, and IL-6) and TLR4/MYD88/NF-kB signaling pathway, but was negatively correlated with IL10. The relative abundances of the Lachnospiraceae NK4A136 group were positively associated with IL- $1 \beta$ and TNF- $\alpha$, while was negatively associated with ZO- 1 . The Romboutsia was positively correlated with IL-6 and NF-kB but was negatively correlated with Claudin- 1 and ZO-1. The relative abundances of Turicibacter significantly negatively correlated with ZO-1. The Escherichia-Shigella was positively associated with pro-inflammation cytokines (IL-1 $\beta$, TNF- $\alpha$, and IL-6) and TLR4/MYD88/NF-kB signaling pathway, while was negatively associated with tight junction proteins (claudin-1, occludin, and ZO-1) and IL-10. The Akkermansia was positively correlated with the pro-inflammation cytokines (IL-1 $\beta$ and TNF$\alpha$ ), Claudin-1, Occludin, and TLR4/MYD88/NF-kB signaling pathway, but was negatively correlated with IL-10 and ZO-1.

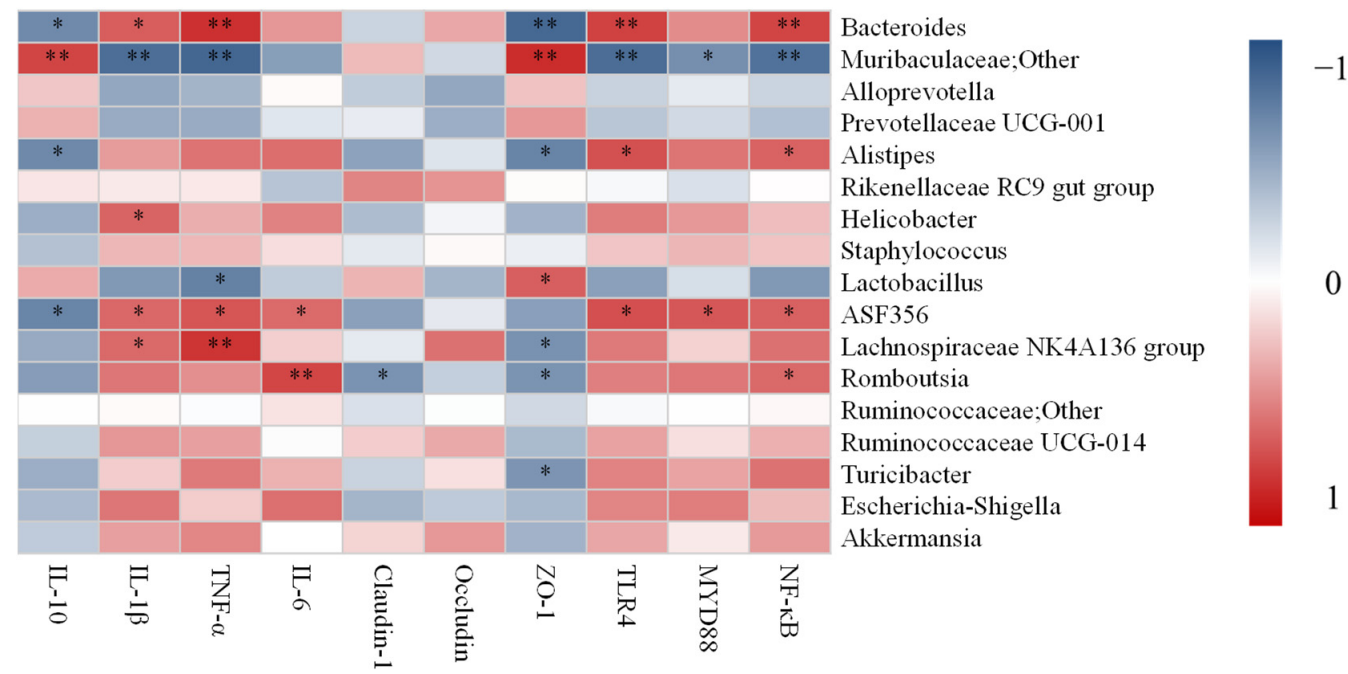

Figure 7. Correlation analysis between UC-related symptoms, related gene expression, and dominant gut microbiota by Spearman. ${ }^{*}$ and ${ }^{* *}$ indicate the associations significant $(p<0.05$ and $p<0.01$, respectively). 


\section{Discussion}

The prevalence of IBD is increasing globally, placing a huge health burden on families and society. At present, traditional drugs can cause side effects, so it is imperative to explore natural and harmless therapeutic agents. A large number of in vitro and in vivo studies have shown that some Bifidobacteria can effectively adjust intestinal dysfunction [23,32]. In this study, hence, we evaluated the alleviation effect of B. lactis XLTG11 on DSS-induced colitis in mice.

DSS model is a typical and standard experimental model of ulcerative colitis [33]. Previous studies reported that DSS treatment exhibited a number of colitis symptoms, such as weight loss, higher DAI score, colon shortening, and increased spleen weight [34]. MPO is an enzyme located in neutrophil granules, which reflects the degree of neutrophil infiltration in colon tissue, and its activity is positively correlated with the degree of inflammation in colon tissue [35]. DSS will damage the intestinal epithelial barrier, infiltrating inflammatory cells, reduce or even disappear goblet cells. In this experiment, it was found that $B$. lactis XLTG11 supplementations could relieve weight loss, decrease DAI score, increase colon length, decrease MPO activity and spleen weight induced by DSS in a dosedependent manner. After the intervention of B. lactis XLTG11, the histopathological score was significantly decreased and the histopathological status of the colon was improved.

The pathogenesis of IBD is related to the dysregulation and hyper-activated intestinal mucosal immune response [35]. It has been reported that the levels of pro-inflammatory cytokines (including IL- $1 \beta$, TNF- $\alpha$, and IL-6) were up-regulated, while the levels of antiinflammatory cytokine IL-10 down-regulated accordingly in the DSS-induced mice [36]. High levels of IL- $1 \beta$ are closely related to the severity of intestinal inflammation and disease activity, and excessive IL-1 $\beta$ can increase intestinal permeability, promote the activation of dendritic cells and macrophages, and play a key role in the pathogenesis of intestinal inflammation [37,38]. TNF- $\alpha$ and IL- 6 are considered to be important mediators of the inflammatory response in patients with IBD. Studies have found that TNF- $\alpha$ increases the expression of epithelial myosin light chain kinase, leading to increased intestinal permeability in patients with intestinal inflammation [39]. IL-6 plays an important role in the intestinal epithelial barrier and can regulate the tight junctions of the intestinal epithelium by activating the claudin-2 gene [40]. Anti-IL- 6 and anti-TNF- $\alpha$ have become therapeutic targets for the abnormal inflammatory response in patients with IBD. IL-10 is a major anti-inflammatory cytokine and plays a crucial role in maintaining gastrointestinal homeostasis [41]. A study showed that the probiotic mixture can significantly increase the expression of IL-10 in DSS-induced mice, which is essential for reducing intestinal inflammation [42]. In the current study, DSS treatment significantly increased the concentrations of IL-1 $\beta$, TNF- $\alpha$, and IL-6, but decreased IL-10 in the MC group compared to that of the NC group. While both dose B. lactis XLTG11 interventions reversed these changes to some extent, and high-dose B. lactis XLTG11 interventions were particularly effective in regulating cytokines.

The intestinal barrier plays an essential role in the maintenance of intestinal homeostasis and the development of intestinal inflammation [43]. Tight junctions mainly include transmembrane proteins (Occludin and Claudins) and accessory proteins (ZO-1 and ZO-2), which are the main components of the intestinal mucosal barrier and affect the permeability and integrity of the intestinal mucosa [44]. The lack of tight junctions will increase the permeability of the intestinal barrier, resulting in the invasion of bacteria and potentially harmful antigens, and then triggering and promoting the occurrence of intestinal inflammation [45]. Here, we found that DSS administration significantly down-regulated the mRNA expression of claudin- 1 and ZO- 1 compared to the NC group, indicating that permeability of the intestinal epithelium may be increased. As expected, $\mathrm{BH}$ supplements were the most effective in upregulating claudin-1, occludin, and ZO-1 expression in DSS-induced mice followed by the BL treatment. In addition, the previous study has also indicated that $B$. longum CCM 7952 could increase the expression of ZO-1 and occludin in the intestinal 
epithelium and reduce colon permeability in DSS-treated mice, which is consistent with our results [46].

To further investigate the potential mechanisms of B. lactis XLTG11 alleviating the symptoms of DSS-induced colitis in mice, we measured the expression of immune pathwayrelated genes in colon tissue. Numerous evidence disclosed that the activation of the TLR4/MYD88/NF- $\mathrm{BB}$ signaling pathway is associated with the pathogenesis of colitis [47,48]. TLR4-mediated signaling pathway performs intracellular signal transduction by recognizing the ligand and then combining with its main adaptive molecule MYD88, which ultimately leads to the activation of the key transcription factor NF- $\mathrm{BB}$ and the secretion of TNF- $\alpha$, IL-6, and other cytokines by effector cells, thus destroying intestinal immune homeostasis, and eventually leading to UC [49-51].

TLR4 is the first discovered transmembrane receptor in the TLR family, which has the functions of regulating immune response and pro-inflammatory [52]. MyD88 signal is an important adaptor protein in the process of TLR4 signal transduction, and it is also the upstream signal molecule of the NF-kB signaling pathway, which in turn triggers the signal cascade, resulting in the activation of downstream NF- $\mathrm{B}$ [53]. NF- $\mathrm{BB}$ is a marker of intestinal mucosal infection, and the level of NF- $\mathrm{KB}$ in colon tissue can reflect the severity of UC disease [54]. Studies have also shown that NF-kB is over-activated in the process of UC, leading to the secretion of pro-inflammatory cytokines, and the accumulation of these inflammatory cytokines is considered to be an important factor in the pathogenesis of colitis $[55,56]$. In this study, the mRNA levels of TLR4, MyD88, and NF-kB were remarkably increased in the MC group compared with the NC group. In particular, these changes were significantly decreased by the treatment of BL and $\mathrm{BH}$. Especially, treatment with the high-dose B. lactis XLTG11 was closer to that of the NC group, which was similar to the research of $\mathrm{Xu}$ et al. [57].

Accumulating studies reported that dysbiosis of the gut microbiota was observed in IBD [58]. The alteration of gut microbiota in patients with IBD is characterized by the reduction of good bacteria and the overgrowth of pathogenic bacteria [59]. Chen et al. demonstrated that $B$. breve could alleviate DSS-induced colitis by regulating the gut microbiota. In the current study, DSS administration increased the Simpson index compared to that in the NC group, which is consistent with the results of sun et al. [60]. However, B. lactis XLTG11 supplementation reversed this trend. At the phylum level, the relative abundance of Firmicutes and Proteobacteria was increased, and the relative abundance of Bacteroidetes was decreased in the MC group compared with the NC group, which is consistent with a previous study [61]. In addition, the increase in the abundance of Proteobacteria is regarded as a microbial signature of gut microbiota imbalance [62]. B. lactis XLTG11 can suppress the increase of Proteobacteria in DSS-treated mice in a dose-dependent manner, and regulate the dysbiosis of gut microbiota to a certain extent.

At the genus level, the high and low dose groups in mice showed an increase in genera containing probiotics, such as Muribaculaceae; Other, Akkermansia, Ruminococcaceae UCG-014, and Lachnospiraceae NK4A136 group. Studies have found that Muribaculaceae; Other has potential benefits in alleviating inflammation, suppressing harmful bacteria, and/or promoting anti-cancer immunity [63]. Our study also demonstrated that Muribaculaceae; Other was positively associated with IL-10 and ZO-1, while was negatively associated with IL-1 $\beta$, TNF- $\alpha$, TLR4, MYD88, and NF-кB. Akkermansia is associated with intestinal immunity and plays an important role in intestinal homeostasis [64]. It has been pointed out that Akkermansia was reduced in patients with IBD, indicating that it may have potential anti-inflammatory effects [65], which was consistent with our study. Ruminococcaceae UCG014 is an SCFA producer with an anti-inflammatory effect, which can protect the intestinal barrier and ameliorate colitis [66]. Recent studies found that probiotics and prebiotics administration increased the levels of the Lachnospiraceae NK4A136 group caused by DSS, which plays a critical role in relieving colitis [67].

In contrast, an opposite trend was observed for some pathogenic genera such as Helicobacter, Escherichia-Shigella, Turicibacter, and Alistipes, in which relative abundance 
was decreased when compared with the MC group. Helicobacter and Escherichia-Shigella are gram-negative bacteria that can damage the immune system and aggravate intestinal infections, which are usually related to the pathogenesis of UC [68]. Also, Chen et al found that the relative abundance of Escherichia-Shigella in DSS-colitis mice was significantly increased, while the administration of Baitouweng decoction could effectively decrease its relative abundance, which was consistent with our research [69]. Bosshard et al. confirmed previously that Turicibacter can affect the immune and invasion ability of mice, and cause subclinical infections in piglets [70]. Alistipes can worsen recurrent abdominal pain and are closely associated with intestinal inflammation [71]. A previous study found that Alloprevotella was increased in DSS induced mice model, which was different from our study [72]. While the role of Alloprevotella in digestive diseases remains unclear as it is currently not reported frequently in these diseases. Lactobacillus is a probiotic that regulates the gut microbiota, but the proportion of Lactobacillus was decreased in the treatment of the $\mathrm{BL}$ and $\mathrm{BH}$ group. Yan et al. also found that Lactobacillus acidophilus administration reduced the relative abundance of Lactobacillus in type 2 diabetes mice [73]. Additionally, the correlation analysis in our results also found that Helicobacter, EscherichiaShigella, Turicibacter, Alistipes were positively correlated with pro-inflammation cytokines (IL-1 $\beta$, TNF- $\alpha$, and IL-6), TLR4, MYD88, and NF-kB, while were negatively correlated with tight junction proteins (claudin-1, occludin, and ZO-1) and IL-10. Therefore, our results demonstrated that $B$. lactis XLTG11 supplementation could effectively suppress DSSinduced colitis in mice by increasing the proportion of beneficial bacteria and decreasing the relative abundance of some pathogenic genera.

\section{Conclusions}

This study showed that B. lactis XLTG11 could alleviate DSS-induced colitis in mice including regulating inflammatory cytokines, protecting intestinal barrier function, inhibiting TLR4/MYD88/NF- $\mathrm{kB}$ activation, and modulating the specific gut microbiota. Our research will offer a theoretical basis and future investigations for probiotics to alleviate colitis.

Supplementary Materials: The following are available online at https:/ /www.mdpi.com/article/ 10.3390 /microorganisms9102093/s1, Figure S1. Gut microbiota composition at the phylum level; Figure S2. Gut microbiota composition at the genus level.

Author Contributions: N.W., G.H. and B.L. conceived the study and designed the project. S.W., B.X. and F.L. helped perform the analysis with constructive discussions. N.W. and B.L. analyzed the data and drafted the manuscript. B.L. helped to revise the manuscript. All authors have read and agreed to the published version of the manuscript.

Funding: This work was supported by the "Hundred, Thousand and Ten Thousand" Science and Technology Major Special Project of Heilongiiang Province: Dairy Products and Meat Processing (No. 2020ZX07B01), the National Natural Science Foundation of China (31801518), Chinese nutrition society-Feihe physique nutrition and health research fund (CNS-Feihe2020A37), Academic Backbone Plan of Northeast Agricultural University (No. 19YJXG10), and the "Young Talents" Project of Northeast Agricultural University (18QC52).

Institutional Review Board Statement: All animal procedures were performed in accordance with the Guidelines for Care and Use of Laboratory Animals of Northeast Agricultural University and the experiments were approved by the Animal Ethics Committee of Northeast Agricultural University (ethic approval code: NEAUEC2001119).

Informed Consent Statement: Not applicable.

Data Availability Statement: Raw sequence datasets from $16 \mathrm{~S}$ ribosomal RNA gene sequencing are available in the SRA database under accession number RJNA766158.

Acknowledgments: We would like to express our gratitude to $\mathrm{Na}$ Li for her instructive advice and useful suggestions on the completion of this study.

Conflicts of Interest: The authors declare no conflict of interest. 


\section{References}

1. Kaplan, G.G.; Ng, S.C. Understanding and Preventing the Global Increase of Inflammatory Bowel Disease. Gastroenterology 2017, 152, 313-321. [CrossRef] [PubMed]

2. Tan, Y.; Zheng, C. Effects of Alpinetin on Intestinal Barrier Function, Inflammation and Oxidative Stress in Dextran Sulfate Sodium-Induced Ulcerative Colitis Mice. Am. J. Med. Sci. 2018, 355, 377-386. [CrossRef] [PubMed]

3. Gophna, U.; Sommerfeld, K.; Gophna, S.; Doolittle, W.F.; Zanten, S. Differences between Tissue-Associated Intestinal Microfloras of Patients with Crohn's Disease and Ulcerative Colitis. J. Clin. Microbiol. 2006, 44, 4136-4141. [CrossRef]

4. Wang, X.; Fan, F.; Cao, Q. Modified Pulsatilla decoction attenuates oxazolone-induced colitis in mice through suppression of inflammation and epithelial barrier disruption. Mol. Med. Rep. 2016, 14, 1173-1179. [CrossRef]

5. Feuerstein, J.D.; Akbari, M.; Tapper, E.B.; Cheifetz, A.S. Systematic review and meta-analysis of third-line salvage therapy with infliximab or cyclosporine in severe ulcerative colitis. Ann. Gastroenterol. Q. Publ. Hell. Soc. Gastroenterol. 2016, 29, 341-347. [CrossRef] [PubMed]

6. Thompson, K.D.; Connor, S.J.; Walls, D.M.; Gollins, J.; Stewart, S.K.; Bewtra, M.; Baumblatt, G.L.; Holubar, S.D.; Greenup, A.-J.; Sechi, A.; et al. Patients with Ulcerative Colitis Are More Concerned About Complications of Their Disease than Side Effects of Medications. Inflamm. Bowel Dis. 2016, 22, 940-947. [CrossRef]

7. Nishida, A.; Inoue, R.; Inatomi, O.; Bamba, S.; Naito, Y.; Andoh, A. Gut microbiota in the pathogenesis of inflammatory bowel disease. Clin. J. Gastroenterol. 2018, 11, 1-10. [CrossRef]

8. Ng, S.C.; Bernstein, C.N.; Vatn, M.H.; Lakatos, P.L.; Loftus, E.V.; Tysk, C.; Colombel, J.F. Geographical variability and environmental risk factors in inflammatory bowel disease. Gut 2013, 62, 630-649. [CrossRef]

9. Pickard, J.M.; Zeng, M.Y.; Caruso, R.; Núñez, G. Gut microbiota: Role in pathogen colonization, immune responses, and inflammatory disease. Immunol. Rev. 2017, 279, 70-89. [CrossRef] [PubMed]

10. Jonsson, A.L.; Bäckhed, F. Role of gut microbiota in atherosclerosis. Nat. Rev. Cardiol. 2017, 14, 79-87. [CrossRef]

11. Lo Presti, A.; Zorzi, F.; Del Chierico, F.; Altomare, A.; Cocca, S.; Avola, A.; de Biasio, F.; Russo, A.; Cella, E.; Reddel, S.; et al. Fecal and Mucosal Microbiota Profiling in Irritable Bowel Syndrome and Inflammatory Bowel Disease. Front. Microbiol. 2019, $10,1655$. [CrossRef]

12. Santoru, M.L.; Piras, C.; Murgia, A.; Palmas, V.; Camboni, T.; Liggi, S.; Ibba, I.; Lai, M.A.; Orrù, S.; Blois, S.; et al. Cross sectional evaluation of the gut-microbiome metabolome axis in an Italian cohort of IBD patients. Sci. Rep. 2017, 7, 9523. [CrossRef]

13. Hansen, R.; Reiff, C.; Russell, R.K.; Bisset, W.M.; Berry, S.H.; Mukhopadhya, I.; Thomson, J.M.; El-Omar, E.; MHold, G.L. Colonic mucosal bacterial diversity of de-novo extensive paediatric ulcerative colitis by next-generation sequencing. Gut. 2011, 60, A146-A147. [CrossRef]

14. Ohkusa, T.; Koido, S. Intestinal microbiota and ulcerative colitis. J. Infect. Chemother. 2015, 21, 761-768. [CrossRef]

15. Ahmed, I.; Roy, B.C.; Khan, S.A.; Septer, S.; Umar, S. Microbiome, Metabolome and Inflammatory Bowel Disease. Microorganisms 2016, 4, 20. [CrossRef]

16. Khani, S.; Hosseini, H.M.; Taheri, M.; Nourani, M.R.; Abbas, A. Probiotics as an Alternative Strategy for Prevention and Treatment of Human Diseases: A Review. Inflamm. Allergy Drug Targets 2012, 11, 79-89. [CrossRef]

17. Panwar, H.; Rashmi, H.M.; Batish, V.K.; Grover, S. Probiotics as potential biotherapeutics in the management of type 2 diabetesprospects and perspectives. Diabetes 2013, 29, 103-112. [CrossRef] [PubMed]

18. Claes, I.; Keersmaecker, S.; Vanderleyden, J.; Lebeer, S. Lessons from probiotic-host interaction studies in murine models of experimental colitis. Mol. Nutr. Food Res. 2011, 55, 1153-1441. [CrossRef] [PubMed]

19. Bron, P.A.; Kleerebezem, M.; Brummer, R.J.; Cani, P.D.; Mercenier, A.; Macdonald, T.T.; Garcia-Ródenas, C.; Wells, J.M. Can probiotics modulate human disease by impacting intestinal barrier function? Br. J. Nutr. 2017, 117, 93-107. [CrossRef] [PubMed]

20. Shanahan, F. Probiotics in perspective. Gastroenterology 2010, 139, 1808-1812. [CrossRef] [PubMed]

21. Yu, R.; Zuo, F.; Ma, H.; Chen, S. Exopolysaccharide-Producing Bifidobacterium adolescentis Strains with Similar Adhesion Property Induce Differential Regulation of Inflammatory Immune Response in Treg/Th17 Axis of DSS-Colitis Mice. Nutrients 2019, 11, 782. [CrossRef] [PubMed]

22. Din, A.U.; Hassan, A.; Zhu, Y.; Zhang, K.; Wang, G. Inhibitory effect of Bifidobacterium bifidum ATCC 29521 on colitis and its mechanism. J. Nutr. Biochem. 2020, 79, 108353. [CrossRef] [PubMed]

23. Chen, Y.; Jin, Y.; Stanton, C.; Paul Ross, R.; Zhao, J.; Zhang, H.; Yang, B.; Chen, W. Alleviation effects of Bifidobacterium breve on DSS-induced colitis depends on intestinal tract barrier maintenance and gut microbiota modulation. Eur. J. Nutr. 2021, 60, 369-387. [CrossRef] [PubMed]

24. Shinozaki, Y.; Yokota, S.; Miwakeichi, F.; Pokorski, M.; Aoyama, R.; Fukuda, K.; Yoshida, H.; Toyama, Y.; Nakamura, M.; Okada, Y. Structural and functional identification of two distinct inspiratory neuronal populations at the level of the phrenic nucleus in the rat cervical spinal cord. Brain Struct. Funct. 2019, 224, 57-72. [CrossRef] [PubMed]

25. Gad-Elkareem, M.A.M.; Abdelgadir, E.H.; Badawy, O.M.; Kadri, A. Potential antidiabetic effect of ethanolic and aqueous-ethanolic extracts of Ricinus communis leaves on streptozotocin-induced diabetes in rats. Peer] 2019, 7, e6441. [CrossRef]

26. Zhao, H.W.; Yue, Y.H.; Han, H.; Chen, X.L.; Lu, Y.G.; Zheng, J.M.; Hou, H.T.; Lang, X.M.; He, L.L.; Hu, Q.L.; et al. Effect of toll-like receptor 3 agonist poly I:C on intestinal mucosa and epithelial barrier function in mouse models of acute colitis. World J. Gastroenterol. 2017, 23, 999-1009. [CrossRef] 
27. Yu, P.; Ke, C.; Guo, J.; Zhang, X.; Li, B. Lactobacillus plantarum L15 Alleviates Colitis by Inhibiting LPS-Mediated NF- $к B$ Activation and Ameliorates DSS-Induced Gut Microbiota Dysbiosis. Front. Immunol. 2020, 11, 575173. [CrossRef]

28. Mago, T.; Salzberg, S.L. FLASH: Fast Length Adjustment of Short Reads to Improve Genome Assemblies. Bioinformatics 2011, 27, 2957-2963. [CrossRef]

29. Caporaso, J.G.; Kuczynski, J.; Stombaugh, J.; Bittinger, K.; Bushman, F.D.; Costello, E.K.; Fierer, N.; Peña, A.; Goodrich, J.K.; Gordon, J.I. QIIME allows analysis of high-throughput community sequencing data. Nat. Methods 2010, 7, 335-336. [CrossRef]

30. Edgar, R.C. UPARSE: Highly accurate OTU sequences from microbial amplicon reads. Nat. Methods 2013, 10, 996-998. [CrossRef]

31. Pelin, Y.; Wegener, P.L.; Pablo, Y.; Jan, G.; Elmar, P.; Christian, Q.; Timmy, S.; Jörg, P.; Wolfgang, L.; Oliver, G.F. The SILVA and "All-species Living Tree Project (LTP)" taxonomic frameworks. Nucleic Acids Res. 2013, 42, 643-648.

32. Claudio, H.C.; Francesca, A.; Alba, R.N.; Teresa, V.; Pablo, M.C.; Abelardo, M.; Patricia, R.M.; Julio, G. Effect of a Ropy Exopolysaccharide-Producing Bifidobacterium animalis subsp. lactis Strain Orally Administered on DSS-Induced Colitis Mice Model. Front. Microbiol. 2016, 7, 868.

33. Zhang, Y.; Brenner, M.; Yang, W.L.; Wang, P. Recombinant human MFG-E8 ameliorates colon damage in DSS- and TNBS-induced colitis in mice. Lab. Investig. A J. Tech. Methods Pathol. 2015, 95, 480-490. [CrossRef]

34. Liu, C.; Zheng, P.; Liu, X.; Yu, Y.; Zhao, Z. Calycosin attenuates dextran sulfate sodium (DSS)-induced experimental colitis. Iran. J. Basic Med. Ences 2017, 20, 1056-1062.

35. Chassaing, B.; Aitken, J.D.; Malleshappa, M.; Vijay-Kumar, M. Dextran sulfate sodium (DSS)-induced colitis in mice. Curr. Protoc. Immunol. 2014, 104, 15.25.1-15.25.14. [CrossRef] [PubMed]

36. Yang, B.; Chen, H.; Gao, H.; Wang, J.; Stanton, C.; Ross, R.P.; Chen, W. Bifidobacterium breve CCFM683 could ameliorate DSS-induced colitis in mice primarily via conjugated linoleic acid production and gut microbiota modulation. J. Funct. Foods 2018, 49, 61-72. [CrossRef]

37. Gong, Z.; Zhao, S.; Zhou, J.; Yan, J.; Wang, L.; Du, X.; Li, H.; Chen, Y.; Cai, W.; Wu, J. Curcumin alleviates DSS-induced colitis via inhibiting NLRP3 inflammsome activation and IL-1 $\beta$ production. Mol. Immunol. 2018, 104, 11-19. [CrossRef]

38. Al-Sadi, R.; Guo, S.; Dokladny, K.; Smith, M.A.; Ye, D.; Kaza, A.; Watterson, D.M.; Ma, T.Y. Mechanism of interleukin-1 $\beta$ induced-increase in mouse intestinal permeability in vivo. J. Interferon Cytokine Res. 2012, 32, 474-484. [CrossRef]

39. Su, L.; Nalle, S.C.; Shen, L.; Turner, E.S.; Singh, G.; Breskin, L.A.; Khramtsova, E.; Khramtsova, G.; Tsai, P.; Fu, Y. TNFR2 Activates MLCK-Dependent Tight Junction Dysregulation to Cause Apoptosis-Mediated Barrier Loss and Experimental Colitis. Gastroenterology 2013, 145, 407-415. [CrossRef] [PubMed]

40. Al-Sadi, R.; Ye, D.; Boivin, M.; Guo, S.; Hashimi, M.; Ereifej, L.; Ma, T.Y. Interleukin-6 Modulation of Intestinal Epithelial Tight Junction Permeability Is Mediated by JNK Pathway Activation of Claudin-2 Gene. PLoS ONE 2013, 9, e85345. [CrossRef]

41. Li, B.; Alli, R.; Vogel, P.; Geiger, T.L. IL-10 modulates DSS-induced colitis through a macrophage-ROS-NO axis. Mucosal Immunol. 2014, 7, 869-878. [CrossRef]

42. Wang, Y.; Xie, Q.; Zhang, Y.; Ma, W.; Xiang, H. Combination of probiotics with different functions alleviate DSS-induced colitis by regulating intestinal microbiota, IL-10, and barrier function. Appl. Microbiol. Biotechnol. 2020, 104, 335-349. [CrossRef] [PubMed]

43. Peterson, L.W.; Artis, D. Intestinal epithelial cells: Regulators of barrier function and immune homeostasis. Nat. Rev. Immunol. 2014, 14, 141-153. [CrossRef]

44. Yang, F.; Wang, A.; Zeng, X.; Hou, C.; Liu, H.; Qiao, S. Lactobacillus reuteri I5007 modulates tight junction protein expression in IPEC-J2 cells with LPS stimulation and in newborn piglets under normal conditions. BMC Microbiol. 2015, 15, 1-11. [CrossRef] [PubMed]

45. Su, L.; Shen, L.; Clayburgh, D.R.; Nalle, S.C.; Sullivan, E.A.; Meddings, J.B.; Abraham, C.; Turner, J.R. Targeted Epithelial Tight Junction Dysfunction Causes Immune Activation and Contributes to Development of Experimental Colitis. Gastroenterology 2009, 136, 551-563. [CrossRef] [PubMed]

46. Srutkova, D.; Schwarzer, M.; Hudcovic, T.; Zakostelska, Z.; Drab, V.; Spanova, A.; Rittich, B.; Kozakova, H.; Schabussova, I. Bifidobacterium longum CCM 7952 Promotes Epithelial Barrier Function and Prevents Acute DSS-Induced Colitis in Strictly Strain-Specific Manner. PLoS ONE 2015, 10, e0134050. [CrossRef]

47. Dong, L.; Li, J.; Liu, Y.; Yue, W.; Luo, X. Toll-like receptor 2 monoclonal antibody or/and Toll-like receptor 4 monoclonal antibody increase counts of Lactobacilli and Bifidobacteria in dextran sulfate sodium-induced colitis in mice. J. Gastroenterol. Hepatol. 2015, 27, 110-119. [CrossRef]

48. Biasi, F.; Leonarduzzi, G.; Oteiza, P.I.; Poli, G. Inflammatory bowel disease: Mechanisms, redox considerations, and therapeutic targets. Antioxid. Redox Signal. 2013, 19, 1711-1747. [CrossRef]

49. He, X.; Wei, Z.; Wang, J.; Kou, J.; Liu, W.; Fu, Y.; Yang, Z. Alpinetin attenuates inflammatory responses by suppressing TLR4 and NLRP3 signaling pathways in DSS-induced acute colitis. Sci. Rep. 2016, 6, 28370. [CrossRef]

50. Lin, S.; Yin, Q.; Zhong, Q.; Lv, F.L.; Yu, Z.; Li, J.Q.; Wang, J.Z.; Su, B.Y.; Yang, Q.W. Heme activates TLR4-mediated inflammatory injury via MyD88/TRIF signaling pathway in intracerebral hemorrhage. J. Neuroinflamm. 2012, 9, 1-14. [CrossRef]

51. Aderem, A. Role of Toll-like receptors in inflammatory response in macrophages. Crit. Care Med. 2001, 29, s16-s18. [CrossRef]

52. Lin, S.; Li, Y.; Shen, L.; Zhang, R.; Yang, L.; Li, M.; Li, K.; Fichna, J. The Anti-Inflammatory Effect and Intestinal Barrier Protection of HU210 Differentially Depend on TLR4 Signaling in Dextran Sulfate Sodium-Induced Murine Colitis. Dig. Dis. Sci. 2017, 62, 1-15. [CrossRef] [PubMed] 
53. Filali, M.; Lalonde, R.; Theriault, P.; Julien, C.; Calon, F.; Planel, E. Cognitive and non-cognitive behaviors in the triple transgenic mouse model of Alzheimer's disease expressing mutated APP, PS1, and Mapt (3xTg-AD). Behav. Brain Res. 2012, $234,334-342$. [CrossRef] [PubMed]

54. Effect of the antioxidant Mesna (2-mercaptoethane sulfonate) on experimental colitis. Dig. Dis. Sci. 2003, 48, 1177-1185. [CrossRef] [PubMed]

55. Lim, S.M.; Jeong, J.J.; Kang, G.D.; Kim, K.A.; Choi, H.S.; Kim, D.H. Timosaponin AIII and its metabolite sarsasapogenin ameliorate colitis in mice by inhibiting NF-kB and MAPK activation and restoring Th17/Treg cell balance. Int. Immunopharmacol. 2015, 25, 493-503. [CrossRef] [PubMed]

56. Xu, Y.L.; Tang, H.L.; Zhu, S.Y.; Peng, H.R.; Qi, Z.T.; Wang, W. RIP3 deficiency exacerbates inflammation in dextran sodium sulfate-induced ulcerative colitis mice model. Cell Biochem. Funct. 2017, 35, 156-163. [CrossRef]

57. Xu, X.; Zhang, L.; Liu, Z.; Yuan, P.; Yuan, H. Therapeutic Efficacy of the Traditional Chinese Medicine Baishaoqiwu on TNBSinduced Colitis is Associated with Down-regulation of the TLR4/MyD88/NF-kB Signaling Pathway. In Vivo 2016, 30, $181-186$.

58. Sánchez, B.; Delgado, S.; Blanco-Míguez, A.; Lourenço, A.; Gueimonde, M.; Margolles, A. Probiotics, gut microbiota and their influence on host health and disease. Mol. Nutr. Food Res. 2017, 61, 1600240. [CrossRef]

59. Yan, P.G.; Li, J.N. Advances in the understanding of the intestinal micro-environment and inflammatory bowel disease. Chin. Med. J. 2020, 133, 834-841. [CrossRef]

60. Sun, M.; Liu, Y.; Song, Y.; Gao, Y.; Zhao, F.; Luo, Y.; Qian, F.; Mu, G.; Tuo, Y. The ameliorative effect of Lactobacillus plantarum-12 on DSS-induced murine colitis. Food Funct. 2020, 11, 5205-5222. [CrossRef]

61. Shi, J.; Du, P.; Xie, Q.; Wang, N.; Li, B. Protective effects of tryptophan-catabolizing Lactobacillus plantarum KLDS 1.0386 against dextran sodium sulfate-induced colitis in mice. Food Funct. 2020, 11, 10736-10747. [CrossRef]

62. Shin, N.R.; Whon, T.W.; Bae, J.W. Proteobacteria: Microbial signature of dysbiosis in gut microbiota. Trends Biotechnol. 2015, 33, 496-503. [CrossRef]

63. Setoyama, H.; Imaoka, A.; Ishikawa, H.; Umesaki, Y. Prevention of gut inflammation by Bifidobacterium in dextran sulfate-treated gnotobiotic mice associated with Bacteroides strains isolated from ulcerative colitis patients. Microbes Infect. 2003, 5, 115-122. [CrossRef]

64. Shang, Q.; Sun, W.; Shan, X.; Jiang, H.; Cai, C.; Hao, J.; Li, G.; Yu, G. Carrageenan-induced colitis is associated with decreased population of anti-inflammatory bacterium, Akkermansia muciniphila, in the gut microbiota of C57BL/6J mice. Toxicol. Lett. 2017, 279, 87-95. [CrossRef]

65. Derrien, M.; Belzer, C.; Vos, W.M.D. Akkermansia muciniphila and its role in regulating host functions. Microb. Pathog. 2017, 106, 171-181. [CrossRef]

66. Huang, J.; Li, S.; Wang, Q.; Guan, X.; Qian, L.; Li, J.; Zheng, Y.; Lin, B. Pediococcus pentosaceus B49 from human colostrum ameliorates constipation in mice. Food Funct. 2020, 11, 5607-5620. [CrossRef]

67. Wang, Y.N.; Meng, X.C.; Dong, Y.F.; Zhao, X.H.; Li, J.N. Effects of probiotics and prebiotics on intestinal microbiota in mice with acute colitis based on 16S rRNA gene sequencing. Chin. Med. J. 2019, 132, 1. [CrossRef]

68. Mukhopadhya, I.; Hansen, R.; El-Omar, E.M.; Hold, G.L. IBD-what role do Proteobacteria play? Nat. Rev. Gastroenterol. Hepatol. 2012, 9, 219-230. [CrossRef] [PubMed]

69. Wright, D.J.; Drasar, B.S. Dysentery in World War 1: Shigella a century on. Lancet 2014, 384, 1651-1653. [CrossRef]

70. Bosshard, P.P.; Zbinden, R.; Altwegg, M. Turicibacter sanguinis gen. nov., sp. nov., a novel anaerobic, Gram-positive bacterium. Int. J. Syst. Evol. Microbiol. 2002, 52, 1263-1266. [PubMed]

71. Saulnier, D.M.; Riehle, K.; Mistretta, T.A.; Diaz, M.A.; Mandal, D.; Raza, S.; Weidler, E.M.; Qin, X.; Coarfa, C.; Milosavljevic, A.; et al. Gastrointestinal Microbiome Signatures of Pediatric Patients With Irritable Bowel Syndrome. Gastroenterology 2011, 141, 1782-1791. [CrossRef] [PubMed]

72. Wang, C.S.; Li, W.B.; Wang, H.Y.; Ma, Y.M.; Zhao, X.H.; Yang, H.; Qian, J.M.; Li, J.N. VSL\#3 can prevent ulcerative colitis-associated carcinogenesis in mice. World J. Gastroenterol. 2018, 24, 4254-4262. [PubMed]

73. Yan, F.; Li, N.; Shi, J.; Li, H.; Li, B. Lactobacillus acidophilus alleviates type 2 diabetes by regulating hepatic glucose, lipid metabolism and gut microbiota in mice. Food Funct. 2019, 10, 5804-5815. [CrossRef] [PubMed] 